\title{
Repression of WT1-Mediated LEF1 Transcription by Mangiferin Governs $\beta$-Catenin-Independent Wnt Signalling Inactivation in Hepatocellular Carcinoma
}

\author{
Hor-Yue Tan ${ }^{a}$ Ning Wanga,b Sha Lia Ming Honga Wei Guo ${ }^{a} \quad$ Kwan Man \\ Chien-shan Cheng ${ }^{\mathrm{a}, \mathrm{d}} \quad$ Zhen Chen ${ }^{\mathrm{d}} \quad$ Yibin Feng ${ }^{\mathrm{a}, \mathrm{b}}$
}

\begin{abstract}
aSchool of Chinese Medicine, Li Ka Shing Faculty of Medicine, The University of Hong Kong. Hong Kong SAR, 'bShenzhen Institute of Research and Innovation, the University of Hong Kong, Shenzhen, 'Department of Surgery, Li Ka Shing Faculty of Medicine, The University of Hong Kong. Hong Kong SAR, dDepartment of Integrative Oncology, Cancer Center, Fudan University, Shanghai, Department of Integrative Oncology, Shanghai Medical College, Fudan University, Shanghai, China
\end{abstract}

\section{Key Words}

Hepatocellular carcinoma • Mangiferin • Wnt signalling • WT1 • LEF1

\begin{abstract}
Background/Aims: The development of hepatocellular carcinoma (HCC) is a complex process which involves deregulation of multiple signalling pathways. The hyper-activation of Wnt signalling promotes sustained expansion, invasion, and neovascularization of HCC. Mangiferin, a natural small molecule present in Mangifera indica L. has been shown to inactivate $\beta$-catenin, which is an indispensable regulator in Wnt pathway. Our study aimed to determine whether mangiferin has any inhibitory effect on HCC and examine how it modulates Wnt signalling. Methods: The tumour inhibitory effect of mangiferin was examined by in vitro cellular models and an in vivo orthotopic HCC implantation model. The genes responsible for mangiferinmediated anti-HCC were delineated by polymerase chain reaction (PCR) microarray. The expression of target genes was further determined by quantitative PCR and immuno-blotting assays. The binding capacity of Wilms' tumour 1 (WT1) to the lymphoid enhancer-binding factor 1 (LEF1) promoter was confirmed by chromatin immunoprecipitation-qPCR. Results: Oral administration of mangiferin inhibited orthotopic tumour growth. Cellular investigations confirmed the dose-dependent inhibition of mangiferin on HCC expansion and invasion. PCR array combined with Gene Ontology analysis revealed that the Wnt pathway was the predominant target of mangiferin and LEFI was the most reduced gene in the Wnt pathway. Overexpression of LEF1 diminished repression of Wnt signalling and reduced proliferation activity in mangiferin-treated HCC cells. The mangiferin-mediated down-regulation of LEF1 was independent of $\beta$-catenin but associated with WT1 protein. WT1 knock-in in HCC cells




\section{Cellular Physiology Cell Physiol Biochem 2018;47:1819-1834 \\ \begin{tabular}{c|c} 
DOI: 10.1159/000491063 & Ond 2018 The Author(s). Published by S. Karger AG, Basel \\
www.karger.com/cpb
\end{tabular}}

Tan et al.: Mangiferin Suppressed HCC via WT1-Mediated LEF1 Deactivation

further enhanced $L E F 1$ expression. Chromatin immunoprecipitation assays revealed that the mangiferin induced repression of LEF1 was associated with decreased occupancy of WT1 on the LEF1 promoter. Conclusion: Our study identifies a novel mechanism of hepatocellular carcinoma inhibition through $\beta$-catenin-independent Wnt signalling, which is regulated by WT1-associated LEF1 repression. The study also highlights mangiferin as a promising Wnt inhibitor for HCC treatment.

(C) 2018 The Author(s)

Published by S. Karger AG, Basel

\section{Introduction}

Liver malignancy is the second leading cause of cancer mortality, after pulmonary carcinoma, and accounted for an estimated 8.1 million deaths worldwide in 2015 [1]. Hepatocellular carcinoma (HCC) is the most common liver malignancy, accounting for $85 \%$ of all liver malignancies, followed by cholangiocarcinoma $(\sim 10 \%)$, angiosarcoma $(<1 \%)$, and hepatoblastoma. HCC is also categorized as a global disease because it may develop in patients with hepatitis B or C virus infections or with other non-viral risk factors such as obesity, diabetes, and alcohol-induced liver disease [2]. The current optimal therapeutic strategy for HCC is surgical resection and liver transplantation. However, these strategies are applicable in only early stage of HCC with relatively small tumour nodules and good liver function as classified by Child-Pugh score [3]. The asymptomatic and rapid growth of HCC has generally led to poor prognosis and low overall survival rates in patients. The short tumour doubling time and rapid tumour progression in advanced stages of HCC remains the major reason for death [4]. Therefore, there is a great need for anti-tumour agents that decelerate HCC tumour progression and work as a pre-transplantation intervention.

Hyper-activation of the Wnt signalling pathway in HCC has been implicated in tumour progression and aggressiveness [5-7]. Yamashita et al. also postulated that the Wnt pathway is indispensable for maintaining the activities of tumour initiating cells [8], and their Wntstimulated gene expression pattern was associated with reduced overall survival in postsurgical HCC patients [9]. The Wnt signalling pathway is initiated by the binding of Wnt ligand to the FZ-LRP5/ 6 receptor that induces a cascade of events that facilitates $\beta$-catenin accumulation and stabilization [10]. The stabilized $\beta$-catenin translocates into the nucleus and interacts with the transcription factor TCF/LEF1 for subsequent Wnt target gene activation [11]. As the hallmark of Wnt signalling, $\beta$-catenin mutations have been detected in more than $40 \%$ of HCC patients [12] and are highly expressed in HBV-related HCC samples [13]. In addition, cytoplasmic retention of $\beta$-catenin is associated with poorer prognosis in HCC [14]. Although critical reviews have indicated that $\beta$-catenin plays a role in carcinogenesis $[15,16], \beta$-catenin-overexpressing mice showed no hepatic tumour formation $[17,18]$. In addition, several instances have reported the activation of $\beta$-catenin-independent Wnt signalling cascade, in which TCF/LEF1 may interact with other proteins such as ALY and Smad3 for subsequent gene transduction [19]. Although little is known about TCF/LEF1 in HCC, it has been shown to be a pre-requisite in Wnt signalling, and its function is closely associated with HCC malignancy [19].

Mangiferin is a glucosylxanthone abundantly available in the leaves and bark of Mangifera indica L., a species in the family of Anacardiaceae, commonly known as mango [20]. Previous pharmacological studies have reported an inhibitory effect of mangiferin on different cancer cell lines such as those from breast cancer, leukaemia, astroglioma, and lung cancer [21]. The anti-tumour effect of mangiferin was primarily attributed to its suppressive effect on inflammation, oxidative stress, and cell-cycle related proteins [22]. Notably, results from a recent study suggested that mangiferin suppressed the active form of $\beta$-catenin, an essential element in the activation of the Wnt pathway [23]. Nonetheless, how Wnt signalling is regulated by mangiferin in inhibiting tumour growth remains unknown.

In this study, we explored the in vivo anti-tumour effect of mangiferin using an orthotopic HCC mouse model with luciferase-expressing cells. We also systemically examined the in vitro inhibitory effect of mangiferin on the survival, growth, migration, and invasion of HCC 


\section{Cellular Physiology Cell Physiol Biochem 2018;47:1819-1834 \begin{tabular}{l|l} 
and Biochemistry Published online: June 28, 2018 & $\begin{array}{l}\text { D) } 2018 \text { The Author(s). Published by S. Karger AG, Basel } \\
\text { www.karger.com/cpb }\end{array}$ \\
\hline
\end{tabular}}

Tan et al.: Mangiferin Suppressed HCC via WT1-Mediated LEF1 Deactivation

cells. Molecular target identification was further performed by PCR based-array and Gene Ontology analysis. The transcriptional regulation of a direct target of mangiferin, lymphoid enhancer binding factor 1 (LEF1) by Wilms' tumour 1 protein (WT1), in the presence and absence of mangiferin, was also investigated.

\section{Materials and Methods}

\section{Cell cultures, plasmid and mangiferin}

The human HCC cell line MHCC97L, which was tagged with a luciferase reporter gene, was gifted by Professor Man Kwan from the Department of Surgery, The University of Hong Kong. The HLF cell line was purchased from Japanese Collection of Research Bioresources cell bank. Both cell lines were cultured in Dulbecco's modified Eagle's medium (Gibco, Waltham, MA, USA) supplemented with 4.5g/L glucose, 10\% foetal bovine serum (Gibco, MA, USA) and 1\% penicillin/streptomycin (Gibco, MA, USA)); and they were kept in a $37^{\circ} \mathrm{C}$ humidified incubator (Thermo Fisher Scientific Inc., Waltham, MA, USA) under $5 \% \mathrm{CO}_{2}$. The DNA plasmid encoding pBABE-puro LEF1 was gifted by Joan Massague (plasmid \#27023; Addgene Inc., Cambridge, MA); and the DNA plasmid expressing pAd/WT1-IRES-nAmCyan was gifted by Edward McCabe (plasmid \#29756, Addgene). Mangiferin was purchased from Sigma-Aldrich Co. (St. Louis, MO, USA). The stock solution of mangiferin $(100 \mathrm{mg} / \mathrm{mL}$ ) was prepared in DMSO (Sigma-Aldrich Co., St. Louis, M.O., USA) and $\mathrm{dH}_{2} \mathrm{O}(1: 9, \mathrm{v} / \mathrm{v})$. For animal administration, mangiferin $(50 \mathrm{mg} / \mathrm{kg})$ was prepared in $0.4 \%$ of sodium carboxyl methyl cellulose (Sigma-Aldrich Co., St. Louis, M.O., USA).

\section{Orthotopic HCC implantation murine model}

Human HCC was implanted in mice as described in our previous study [24]. Briefly, an ectopic xenograft of HCC was first established by subcutaneously inoculating luciferase-tagged MHCC97L cells (5 $\square$ $10^{6}$ cells) into the right flank of an athymic BALB/c-nu/nu mouse. The tumours were allowed to grow to 10 $\mathrm{mm}$ in diameter and then the mouse was sacrificed. The subcutaneously grown HCC tumour was removed and cut into 1- $\mathrm{mm}^{3}$ tumour fragments. Bilateral subcostal skin and muscle incisions were made in another BALB/c-nu/nu mice to expose the entire liver. A tumour fragments was then orthotopically implanted into the left lobe of the liver. One week after this surgery, the recipient mouse was then examined using the IVIS Spectrum imaging system (Perkin Elmer Inc., Waltham, MA, USA).) to observe for bioluminescence, taken as an indication of tumour growth. In brief, mice were anaesthetized and intraperitoneally injected with 15 mg/mL VivoGlo luciferin (\#P1041; Promega, Madison, WI USA). Mice showing luciferase signals were randomized to receive a control vehicle $(n=5)$ or mangiferin $(50 \mathrm{mg} / \mathrm{kg} / 2$ days, orally; $\mathrm{n}=5)$. Tumour growth was monitored weekly with the IVIS Spectrum imaging system. All mice were sacrificed after 5 weeks of receiving the control vehicle of mangiferin and the hepatic tumours were excised for further histological analysis. The animal procedures described in this study were approved by the Committee on the Use of Live Animals in Teaching and Research, The University of Hong Kong, Hong Kong.

\section{Bromodeoxyuridine (BrdU) incorporation assay}

BrdU incorporation assay (Thermo Fisher Scientific Inc., Waltham, MA, USA) was performed according to the manufacturer's instructions. In brief, the cells were incubated with BrdU labelling solution for 2 hours before fixation with 3.7\% formaldehyde (Sigma-Aldrich, St. Louis, M.O., USA). BrdU-labelled cells were then permeabilised, washed, and incubated with anti-BrdU antibody overnight. The cells were further incubated with FITC-conjugated secondary antibody and then counterstained with DAPI (Thermo Fisher Scientific Inc., USA). The cells were visualized under a fluorescence microscope (Olympus, Tokyo, Japan) and the percentage of cells with incorporated BrdU was calculated by dividing the number of stained cell by stained plus unstained cells in five areas of each dish.

\section{Cell cycle analysis}

The vehicle- and mangiferin-treated cells were fixed in cold 70\% ethanol. The fixed cells were incubated with $5 \mu \mathrm{g} / \mathrm{mL}$ propidium iodide (Thermo Fisher Scientific Inc., Waltham, MA, USA) for 30 min prior to analysis on a FACS Canto II flow cytometer (BD and Co., Franklin Lakes, NJ, USA). Cell cycle distribution was analysed with FlowJo analysis software and the percentage of cells in each cycle was expressed as mean \pm standard deviation. 


\section{Cellular Physiology Cell Physiol Biochem 2018;47:1819-1834 \begin{tabular}{l|l} 
and Biochemistry Published online: June 28, 2018 & $\begin{array}{l}\text { D) } 2018 \text { The Author(s). Published by S. Karger AG, Basel } \\
\text { www.karger.com/cpb }\end{array}$
\end{tabular}}

Tan et al.: Mangiferin Suppressed HCC via WT1-Mediated LEF1 Deactivation

\section{Clonogenic formation assay}

HCC cells $\left(5 \times 10^{2}\right.$ cells $)$ were incubated with vehicle or mangiferin in a humidified incubator for 14 days. At the end of this time, the culture medium in each well was removed, and $0.5 \%$ crystal violet (BD, Franklin Lakes, NJ, USA) was added. After 30 min of incubation, the plates were rinsed with tap water and dried in room air. The images of colony-filled wells were captured, and the colonies in each group were counted and analysed.

\section{Real-time Quantitative PCR}

Total RNA from treated cells was purified using the RNeasy Plus Mini reagent kit (Qiagen, Hilden, Germany) and reverse-transcribed using PrimeScript RT master mix (Takara Co., Shiga, Japan). Then, quantitative PCR was performed using SYBR Green master mix (Takara Co., Shiga, Japan) ) and the RT ${ }^{2}$ Profiler human liver cancer PCR array (Qiagen, Hilden, Germany) on a Light Cycler 480 PCR System (Roche Ltd., Basel, Switzerland), as per the manufacturers' instructions. The relative expression of a target gene transcript after normalization to a reference GAPDH transcript were calculated. The primer sequences used in the study are shown in Table 1.

\section{Histology and immunofluorescent analysis}

Paraffin-embedded sections (thickness, $4 \mu \mathrm{m}$ ) were mounted on slides, deparaffinised with xylene, and rehydrated with decreasing concentrations of alcohol (100\% to $70 \%)$. For haematoxylin and eosin staining, the slides were incubated in Mayer's haematoxylin (Sigma-Aldrich Co., St. Louis, M.O., USA) for 5 min, followed by $30 \mathrm{~s}$ of incubation in $1 \%$ acid alcohol and $0.25 \%$ eosin Y solution (Sigma-Aldrich Co., St. Louis, M.O., USA). After staining, slides were mounted on Canada balsam (Sigma-Aldrich Co., St. Louis, M.O., USA) prior to analysis on a BX43 light microscope (Olympus, Tokyo, Japan). The histologic growth pattern of the hepatic tumour was documented.

For immunofluorescence staining, the deparaffinised slides were incubated in pre-heated $10 \mathrm{mM}$ citrate buffer (Sigma-Aldrich Co., St. Louis, M.O., USA) for epitope retrieval prior to $30 \mathrm{~min}$ of incubation with $10 \%$ goat serum containing blocking buffer. Slides were then incubated overnight at $4{ }^{\circ} \mathrm{C}$ with antiCD31 (1:50, \#ab28364; Abcam Inc., Cambridge, United Kingdom) or anti-Ki67 (1:100, \#ab15580; Abcam) antibody. The next day, the tissue was incubated for $2 \mathrm{~h}$ with Alexa-Fluor 488 conjugated anti-mouse IgG (1:500; Invitrogen Corp., Carlsbad, CA USA). The slides were counterstained with DAPI then mounted with fluorescent mounting medium (Dako A/S Glostrup, Denmark). The micro vessel density or Ki67-positive cell count was determined by first screening for the hot spot area under magnification of $40 \mathrm{x}$ followed by cell counting at five hotspot areas under a magnification of 200x. The mean count of five microscopic field areas was used as the absolute value of micro vessel density or Ki67-positive cells per high power field.

Table 1. Primers used in this study

\begin{tabular}{|c|c|c|c|c|}
\hline Gene list & Accession Number & Forward sequence & Reverse sequence & Product Size (bp) \\
\hline LEF1 & NM_001130713 & CCTGGTCCCCACACAACTG & GGCTCCTGCTCCTTTCTCTG & 131 \\
\hline CIAP1 & NM_001166 & AGCTAGTCTGGGATCCACCTC & GGGGTTAGTCCTCGATGAAG & 175 \\
\hline Survivin & NM_001297584 & AGAACTGGCCCTTCTTGGAGG & СTTTTTATGTTCCTCTATGGGGTC & 170 \\
\hline MCL1 & NM_001197320 & AAGCCAATGGGCAGGTCT & TGTCCAGTTTCCGAAGCAT & 472 \\
\hline PIN1 & NM_006221 & AAGATGGCGGACGAGGAG & CACTCAGTGCGGAGGATGAT & 491 \\
\hline YAP1 & NM_001130145 & CGCTCTTCAACGCCGTCA & AGTACTGGCCTGTCGGGAGT & 131 \\
\hline MYC & NM_001354870 & AAACACAAACTTGAACAGCTAC & АTTTGAGGCAGTTTACATTATGG & 188 \\
\hline MMP2 & NM_001127891 & GGCCCTGTCACTCCTGAGAT & GGCATCCAGGTTATGGGGGA & 474 \\
\hline Axin 2 & NM_015732 & AGTGTGAGGTCCACGGAAAC & CTGGTGCAAAGACATAGCCA & 103 \\
\hline CCND 1 & NM_053056 & TGAACTACCTGGACCGCT & GCCTCTGGCATTTTGGAG & 268 \\
\hline WT1 & NM_000378 & GATAACCACACAACGCCCATC & CACACGTCGCACATCCTGAAT & 90 \\
\hline CTNNB1 & NM_001098209 & AAAATGGCAGTGCGTTTAG & TTTGAAGGCAGTCTGTCGTA & 100 \\
\hline АСтв & NM_007393 & GСTTCTCCTTAATGTCACGC & CССACACTGTGCCCATCTAC & 168 \\
\hline \multicolumn{2}{|c|}{$\begin{array}{l}\text { LEF1 promoter } \\
\text { (for ChIP-gPCR) }\end{array}$} & GCAGCACTTAGAAGGGGCTT & CGTCTTCCCGGGGTTACTTC & 147 \\
\hline
\end{tabular}




\section{Cellular Physiology Cell Physiol Biochem 2018;47:1819-1834 \begin{tabular}{l|l} 
and Biochemistry Published ondine: June 28, 2018 & $\begin{array}{l}\text { (c) } 2018 \text { The Author(s). Published by S. Karger AG, Basel } \\
\text { www.karger.com/cpb }\end{array}$
\end{tabular}}

Tan et al.: Mangiferin Suppressed HCC via WT1-Mediated LEF1 Deactivation

\section{Immunocytostaining}

HCC cells were seeded on confocal dishes (Thermo Fisher Scientific Inc., Waltham, MA, USA) and incubated with vehicle or mangiferin for $48 \mathrm{~h}$. The treated cells were then fixed, blocked, and incubated with anti-LEF1 (C12A5) (1:200, \#2230; Cell Signaling Technology Co., Danvers, MA USA) overnight. The following day, Alexa-Fluor 488 conjugated anti-rabbit IgG (1:500, Invitrogen, Carlsbad, CA, USA) was applied to the dishes for $2 \mathrm{~h}$ prior to counterstaining with DAPI. Specimens were visualized under an LSM 780 confocal microscope (Carl Zeiss AG, Oberkochen, Germany).

\section{Plasmid DNA transfection}

HCC cells were seeded on reduced-serum supplemented media before transfection. After one day's growth, the cells were incubated with $5 \mu \mathrm{g} / \mu \mathrm{L}$ of plasmid in Lipofectamine 2000 Transfection reagent (Invitrogen, Carlsbad, CA, USA) according to the manufacturer's instructions.

\section{Immunoblotting}

Cell lysates were prepared by lysing HCC cells in RIPA lysis and extraction buffer (Thermo Fisher Scientific Inc., Waltham, MA USA) complemented with proteinase inhibitor cocktail (Sigma-Aldrich, St. Louis, M.O., USA) and phosphatase inhibitor (Cell Signaling Technology, Danvers, MA, , USA). Nuclear extraction of HCC cells was performed using cell extraction buffer (Thermo Fisher Scientific Inc., Waltham, MA, USA) according to the manufacturer's instructions. Equal amounts of denatured protein or nuclear lysates were subject to sodium dodecyl sulfate polyacrylamide gel electrophoresis (SDS-PAGE; Bio-Rad, Hercules, CA) and then electro-transferred onto PVDF membrane (Bio-Rad Laboratories Inc., Hercules, CA). Blocking buffer containing 5\% BSA was applied to the membrane for $2 \mathrm{~h}$ prior to overnight incubation with the relevant antibodies: anti-LEF1 (C12A5) (1:1000, Cell Signaling Technology, Danvers, MA, USA), anti-WT1 (C-19) (1:500, Santa Cruz Biotechnology, Dallas, TX, USA), anti-Lamin B1 (1:500, ab16048; Abcam, Cambridge, UK) and anti-GAPDH (14C10) (1:1000, Cell Signaling Technology, USA). HRP-conjugated secondary antibody (1:2000, Cell Signaling Technology, USA) was applied to the membrane for $2 \mathrm{~h}$ and then bands were visualized using the Amersham ECL chemiluminescence detection reagent (Sigma-Aldrich Co., St. Louis, M.O., USA).

\section{Chromatin immunoprecipitation (ChIP) assay}

ChIP assay was performed using the EZ-Magna ChIP A-Chromatin Immunoprecipitation kit (Millipore, Darmstadt, Germany) according to the manufacturer's instructions. Briefly, the cells were first cross-linked in formaldehyde and lysed in cell and nuclear lysis buffer. The cell lysates were sonicated for 15 cycles of 7-s and 10 -s pulses (40\% amplitude) to shear the cross-linked DNA, and then incubated overnight with antiWT1 (C-19) (Santa Cruz Biotechnology, Dallas, TX, USA) or IgG control, and protein A magnetic beads. WT1/ DNA complexes were precipitated, and reverse cross-linked by incubation with elution buffer supplemented with proteinase $\mathrm{K}$ at $62^{\circ} \mathrm{C}$. The DNA was then purified by applying the sample to a DNA separation column. The binding capacity of WT1 to the LEF1 promoter was analysed by qPCR and the shear DNA sample served as an input control. The promoter binding region was verified using an Applied Biosystems 3730xl DNA analyser (Thermo Fisher Scientific Inc., Waltham, MA, USA).

\section{Analysis of GEO and TCGA databases}

The microarray dataset under accession number GDS4887 [25] was downloaded from the publicly accessible Gene Expression Omnibus (GEO) database. Expression patterns of LEF1 in tumour and nontumor regions of HCC specimens were analysed and compared. Gene expression arrays of LEF1 and WT1 in patients with HCC were extracted from the open-access The Cancer Genome Atlas (TCGA) database using cBioPortal $[26,27]$. In the cBioPortal interface, the study of "Liver Hepatocellular Carcinoma (TCGA, Provisional)" and genome profiles of "mRNA Expression z-Scores (RNA Seq V2 RSEM)" were selected. For the gene set of interest, "LEF1" or "WT1" was entered. The dataset included data from 442 patients' samples and the mRNA expression (in log 2 level) was analysed according to the patients' overall survival and histological tumour grade. The correlation between gene expressions and HCC patients' overall survival was used to plot Kaplan-Meier curves. 


\section{Cellular Physiology Cell Physiol Biochem 2018;47:1819-1834 \begin{tabular}{l|l} 
DOI: 10.1159/000491063 & $\begin{array}{l}\text { O } 2018 \text { The Author(s). Published by S. Karger AG, Basel } \\
\text { www.karger.com/cpb }\end{array}$
\end{tabular}}

Statistical analysis

Data from all experiments were expressed as mean \pm standard deviation. The data between groups was analysed using a one-way analysis of variance (ANOVA) or student's $t$ test. A $p$ value less than 0.05 was considered an indicator of statistical significance.

\section{Results}

Oral administration of mangiferin suppressed orthotopic hepatic tumour growth in vivo

To investigate whether mangiferin suppresses hepatocellular carcinoma growth and progression, the orthotopic HCC implantation murine model was used and the growth of hepatic tumours derived from luciferase-tagged MHCC97L cells were monitored. Fiveweek oral administration of mangiferin $(50 \mathrm{mg} / \mathrm{kg} / 2$ days $)$ decelerated hepatic tumour growth. Tumour regression was apparent after 3 weeks of mangiferin treatment (Fig. $1 \mathrm{~A}$ ) and continued through to completion of treatment (Fig. 1B). In addition, body weight remained similar between the two groups throughout the experimental period, suggesting that mangiferin was not toxic to the mice (Fig. 1C). Further histological analyses showed that control mice had irregular and invasive growth of the hepatic tumours. The elusive

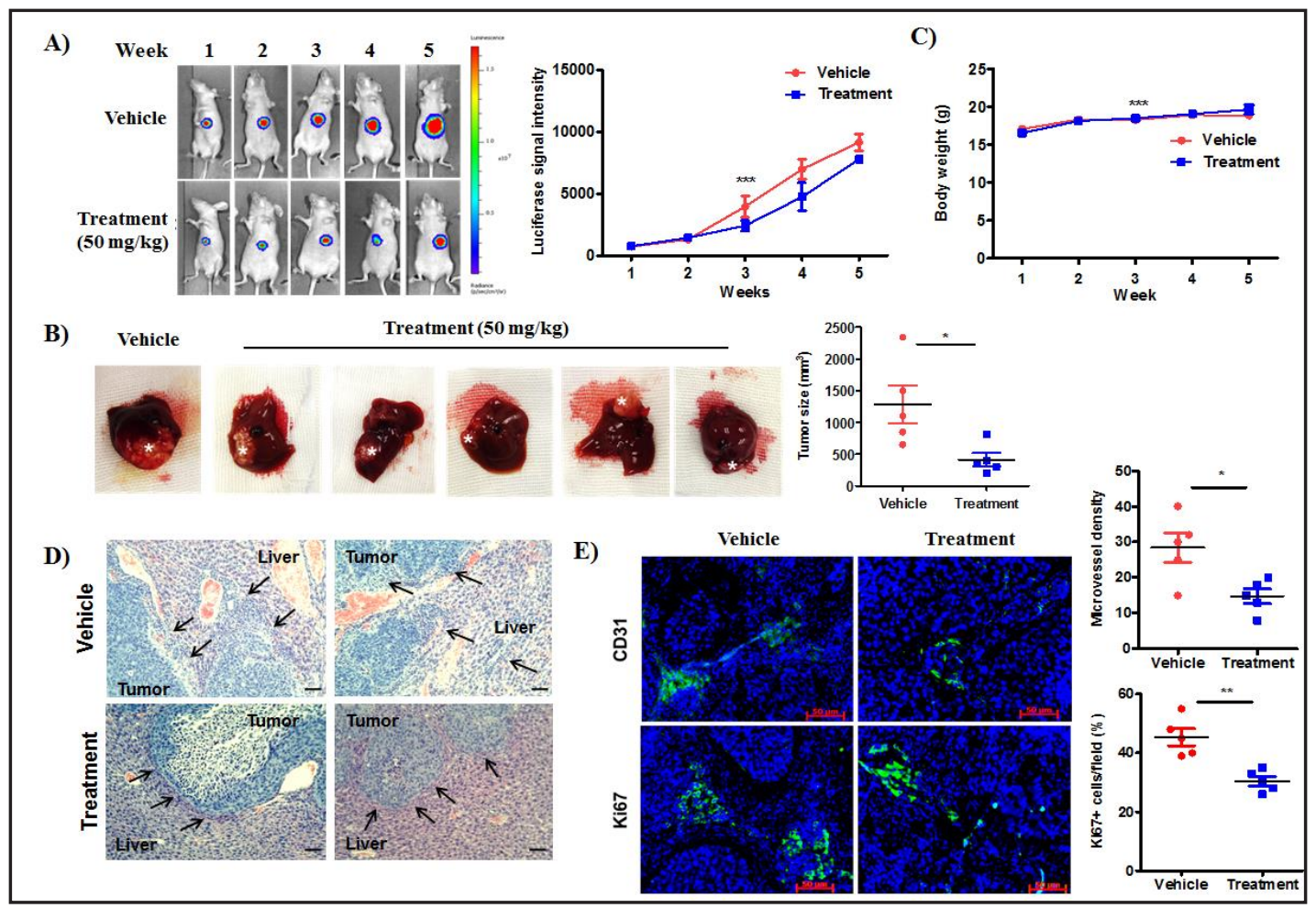

Fig. 1. Oral administration of mangiferin reduced orthotopic hepatic tumour growth. A: Luciferase-tagged MHCC97L cells were orthotopically implanted in mouse liver and tumour growth was monitored by weekly live cell imaging. The bioluminescence signal was significantly lower in the mangiferin-treated group than in the control group after week 3 of treatment. B: Representative images of excised hepatic tumour after 5 weeks of mangiferin intervention. * indicates the location of tumour growth. Tumours were significantly smaller in mice receiving mangiferin $(50 \mathrm{mg} / \mathrm{kg} / 2$ days, p.o.) than in those receiving the control vehicle. C: Body weight of mice were monitored every week. There were no significant changes in body weight during the experimental period. D: Representative images of hepatic tumour tissues (H\&E staining). Arrows indicate the invasive growth front. E: Representative immunohistochemistry images of hepatic tumour tissues labelled with anti-CD31 and anti-Ki67 antibodies. The microvessel density and Ki67 positive cells were significantly reduced in mice receiving mangiferin. ${ }^{*} \mathrm{p}<0.05 ;{ }^{* *} \mathrm{p}<0.01 ;{ }^{* * *} \mathrm{p}<0.001$. 


\section{\begin{tabular}{lll} 
Cellular Physiology & \multicolumn{1}{c}{ Cell Physiol Biochem 2018;47:1819-1834 } \\
DOI: 10.1159/000491063 & O 2018 The Author(s). Published by S. Karger AG, Basel
\end{tabular}

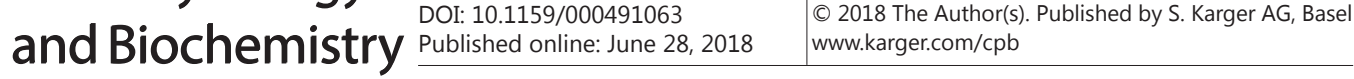 \\ Tan et al.: Mangiferin Suppressed HCC via WT1-Mediated LEF1 Deactivation}

border between hepatic and tumour tissue, with tumour cells infiltrating the vascular lumen suggested rapid and invasive growth of HCC. In contrast, the tumours in the mangiferin group displayed a non-invasive growth pattern with a distinct border between the hepatic and tumour tissue, suggesting that the cells had less invasive properties after mangiferin treatment (Fig. 1D). The average vessel area and proliferative populations, as evidenced by CD31 and Ki67, respectively, were significantly smaller in the mangiferin group than in the control group (Fig. 1E). In sum, mangiferin administration suppressed orthotopic hepatic tumour growth in vivo.

\section{Mangiferin intervention reduced HCC cellular proliferation and invasion in vitro}

Observing the significant inhibition of orthotopic tumour growth by mangiferin, we further investigated the inhibitory role of mangiferin on various functions in HCC cells. Two human hepatocellular carcinoma cell lines, MHCC97L and HLF were used. Cytotoxicity assay revealed that mangiferin induced no significant toxicity (more than $75 \%$ of cell viability) in HCC cells (Fig. 2A). However, $48 \mathrm{~h}$ of incubation with mangiferin at doses above $200 \mu \mathrm{g} / \mathrm{mL}$ led to gradual death of HLF but not MHCC97L cells. Although mangiferin at doses under 200 $\mu \mathrm{g} / \mathrm{mL}$ were not cytotoxic to HCC cells, a dose of $120 \mu \mathrm{g} / \mathrm{mL}$ reduced cell proliferation, as determined by BrdU incorporation (Fig. 2B). Cell cycle analysis further confirmed the delay of the G1/S transition in HCC cells subject to mangiferin treatment, in a dose-dependent manner (Fig. 2C). These results suggest that mangiferin might defer HCC cell proliferation rate by halting the cells in G1 phase, without affecting cell viability. Consistently, clonogenic assays also showed reduced colony formation in MHCC97L and HLF cells following treatment with $120 \mu \mathrm{g} / \mathrm{mL}$ of mangiferin for 14 days (Fig. 2D). In sum, these results indicate that mangiferin decreases the reproductive capacity of HCC cells. Surprisingly, mangiferin also reduced the migratory and chemotactic properties of HCC cells in a dosedependent manner, as evidenced from the wound healing (Fig. 3A \& 3B) and trans-well assays (Fig. 3C). In sum, these results demonstrated that mangiferin may in-

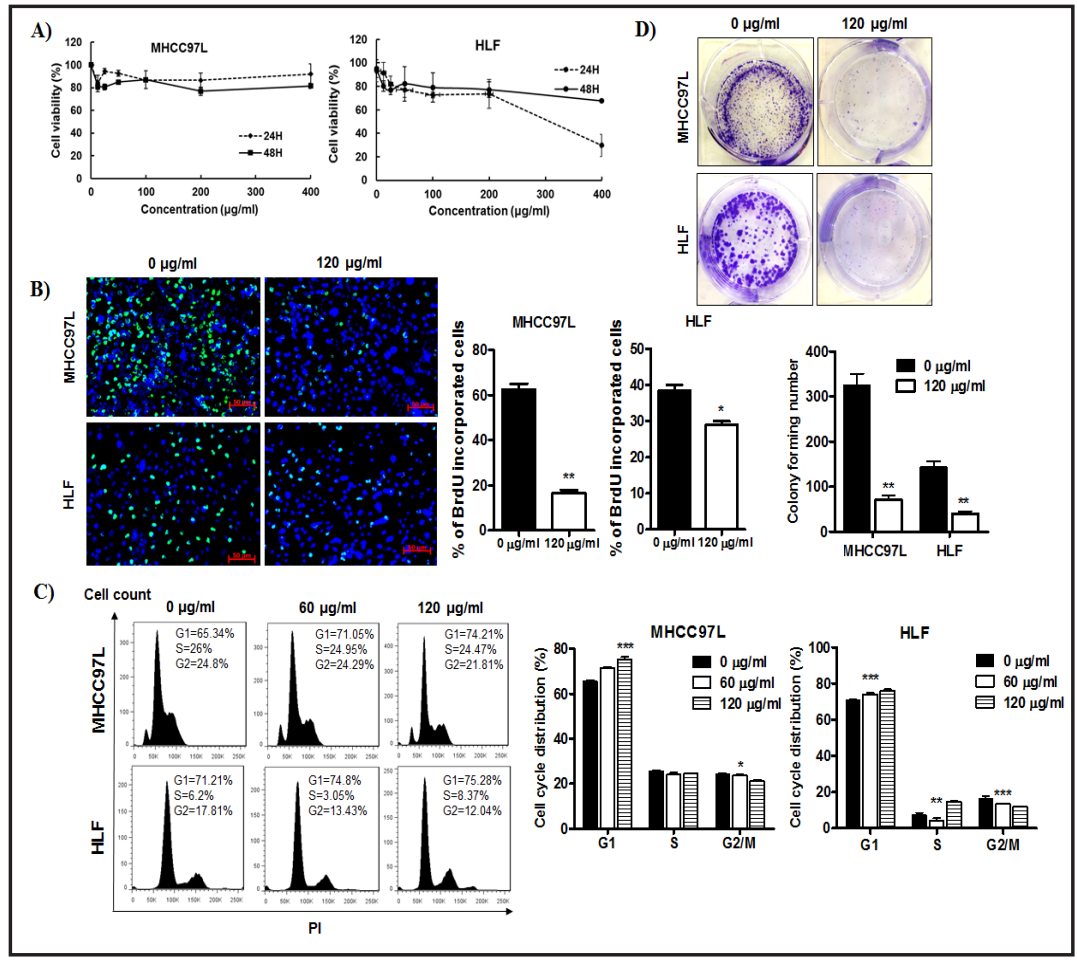

Fig. 2. Non-toxic doses of mangiferin inhibited HCC cell proliferation. A: The cellular toxicity curve of MHCC97L and HLF after mangiferin treatment in a doseand time-dependent manner. There was no potent toxicity of mangiferin on MHCC97L and HLF cells at doses below $200 \mu \mathrm{g} / \mathrm{mL}$. B: Representative analysis of HCC cells stained with BrdU. Mangiferin at $120 \mu \mathrm{g} / \mathrm{mL}$ significantly reduced the number of HCC cells that incorporated BrdU. C: Cell cycle distribution analysis showed a dose-dependent increase in PI-labelled MHCC97L and HLF cells at G1/S phases upon mangiferin treatment. D: Representative images of crystal violet-stained HCC cells. Mangiferin attenuated colony growth after 14 days of culture. ${ }^{* *} \mathrm{p}<0.01 ;{ }^{* * *} \mathrm{p}<0.001$. 
terrupt HCC cell growth through various mechanisms.

Reduced LEF1 by mangiferin is associated with increased survival in HCC patients

To better understand how mangiferin inhibits HCC growth, we analysed the cellular action of mangiferin using PCR microarrays targeting major oncogenic and suppressive proteins in HCC (Fig. 4A). Applying a fold-change of 2.5 as a cut-off, we noted that, upon mangiferin treatment, 33 genes were down-regulated and 9 were up-regulated in MHCC97L cells (Fig. 4B and Table 2). Gene ontology (GO) analysis of expression profiles indicated that mangiferin treatment but not the

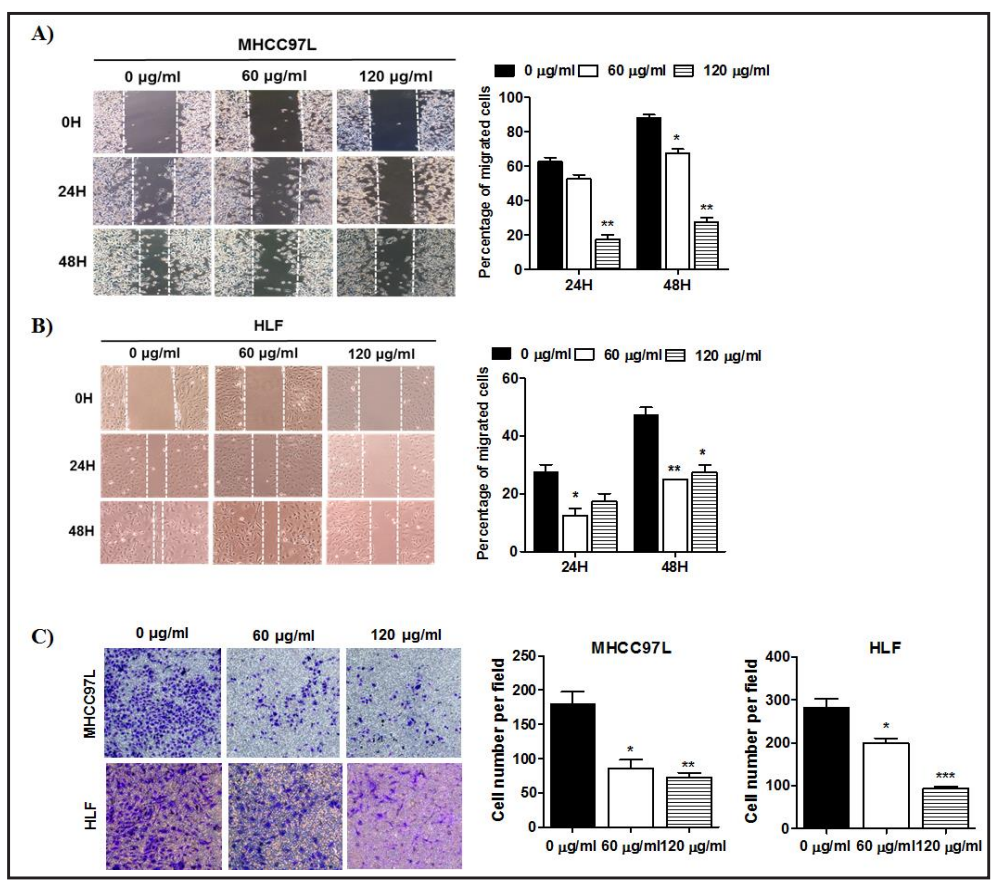

Fig. 3. Mangiferin treatment reduced the invasive and migratory properties of HCC cells. A: Representative images of MHCC97L cells after 24 and 48 $\mathrm{h}$ of incubation with vehicle or mangiferin. Dose- and time-dependent reduction of the MHCC97L gap closure was observed after mangiferin treatment. B: Mangiferin treatment also decreased the gap closure of HLF cells in a dose- and time-dependent manner. C: Representative images of transwell chambers. Mangiferin treatment compared to the control vehicle reduced the density of invasive HCC cells. ${ }^{*} \mathrm{p}<0.05 ;{ }^{* *} \mathrm{p}<0.01 ;{ }^{* * *} \mathrm{p}<0.001$.

Table 2. Liver cancer genes regulated by mangiferin

\begin{tabular}{|c|c|c|c|}
\hline Down-regulated genes & Fold regulation & Up-regulated genes & Fold regulation \\
\hline ADAM 17 & -2.151 & BCL2 & 6.0839 \\
\hline AKT1 & -2.0209 & CDKN2A & 4.8736 \\
\hline BCL 2 L1 & -3.8504 & DAB2IP & 2.9383 \\
\hline BID & -3.3058 & FLT1 & 4.8736 \\
\hline BIRC5 & -3.1275 & HGF & 4.8736 \\
\hline CCND1 & -2.0491 & HHIP & 2.6299 \\
\hline CCND2 & -5.4453 & SFRP2 & 4.8736 \\
\hline CDKN1A & -2.6299 & SOCS1 & 2.4538 \\
\hline CFLAR & -3.1711 & TERT & 4.8736 \\
\hline CXCR4 & -2.8979 & & \\
\hline DLC1 & -4.976 & & \\
\hline EGF & -2.1962 & & \\
\hline EGFR & -2.8779 & & \\
\hline FZD7 & -2.1214 & & \\
\hline GADD45B & -4.4847 & & \\
\hline HRAS & -2.181 & & \\
\hline IGF2 & -4.0418 & & \\
\hline IGFBP1 & -2.7606 & & \\
\hline IGFBP3 & -4.1267 & & \\
\hline LEF 1 & -44.1702 & & \\
\hline MCL1 & -2.2894 & & \\
\hline MTDH & -2.0634 & & \\
\hline MYC & -2.2894 & & \\
\hline NFKB1 & -2.5403 & & \\
\hline OPCML & -2.8382 & & \\
\hline PTEN & -2.4708 & & \\
\hline PTGS2 & -6.255 & & \\
\hline RASSF1 & -3.7974 & & \\
\hline RHOA & -2.0069 & & \\
\hline RUNX3 & -4.302 & & \\
\hline TGFB1 & -2.151 & & \\
\hline TNFSF10 & -2.42 & & \\
\hline WT1 & -5.4076 & & \\
\hline
\end{tabular}


control vehicles was associated with a significant enrichment of genes involved in Wnt pathway regulation (Fig. 4C). Noting that mangiferin potentially reduced proliferation-related genes in MHCC97L cells, we used quantitative PCR to further validate the mRNA expression of six related genes in orthotopic hepatic tumour tissues. The expression levels of these genes were reduced in tumours from mice treated with mangiferin but not in tumours from mice treated with the control vehicle (Fig. 4D). This finding suggests a potent inhibitory effect of mangiferin on tumour proliferation. Of the 6 deregulated genes, the expression of LEF1 was the most significantly suppressed. A similar downregulation profile of LEF1 mRNA was also observed in HLF cells treated with mangiferin (Fig. 4E).

Subsequently, we sought to analyse the clinical relevance of LEF1 in HCC patients using 40 cases of paired tumorous and non-tumorous samples extracted from the TCGA liver cancer transcriptome dataset. The expression of LEF1 was significantly higher in tumorous hepatic tissue than in non-tumour hepatic tissue (Fig. 4F). Kaplan-Meier analysis indicated that patients with high expression of LEF1 had significantly lower overall survival rates than patients with low LEF1 expression (Fig. 4G). In addition, increased LEF1 expression was

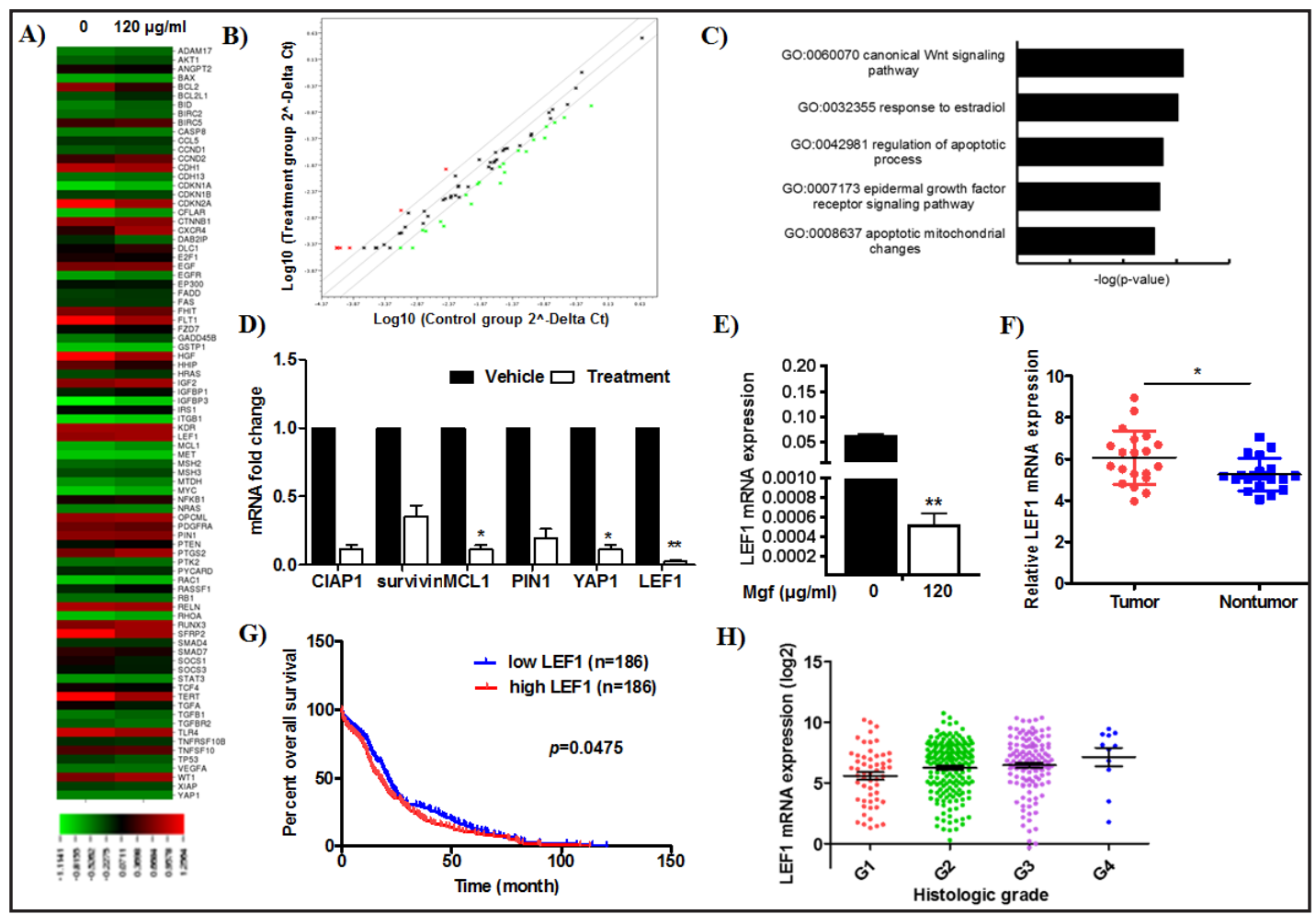

Fig. 4. Mangiferin reduced LEF1 expression in MHCC97L cells. A: MHCC97L cells treated with vehicle or mangiferin were subjected to PCR array analysis. Heat map shows differentially expressed genes between the control and treatment groups. B: Scatter plot using a fold-change of 2.5 as a cut-off. Mangiferin treatment was associated with down-regulation of 33 genes and up-regulation of 9 genes. C: Gene ontology analysis of the gene expression profiles that were distinct between the control and treatment groups. D: Six mangiferin target genes related to cellular proliferation were selected. The relative mRNA fold change in hepatic tumour tissue, as determined by RT-qPCR, is shown for the control and treatment groups. E: LEF1 mRNA expression in HLF cells. Mangiferin significantly reduced LEF1 expression. F: LEF1 mRNA expression in healthy subjects $(n=20)$ and HCC patients $(n=20)$. G: Overall survival rates of HCC patients with respect to low-LEF1 ( $\mathrm{n}=186$ patients) and high-LEF1 ( $\mathrm{n}=186$ patients) mRNA levels. H: Increased LEF1 expression was associated with advanced pathological stages in HCC patients. LEF1 mRNA expression (in log 2 level) in 442 patients' samples extracted from TCGA database correlated with the histologic grade of the neoplasm (based on the grading criteria established by the American Joint Committee of Cancer [AJCC]). ${ }^{*} \mathrm{p}<0.05$; ${ }^{* *} \mathrm{p}<0.01 ;{ }^{* * *} \mathrm{p}<0.001$. 
associated with advanced pathological grade, according to the grading criteria established by the American Joint Committee of Cancer (AJCC) (Fig. 4H). This finding suggests that LEF1 expression may be a negative prognostic indicator for HCC patients. Overall, these results indicate that downregulation of LEF1 - a critical gene correlated to HCC patient survivalby mangiferin, contributes to its inhibitory effect on HCC progression.

\section{Mangiferin blocked nuclear translocation and trans-activated gene expression}

LEF1 expression is a prerequisite of the Wnt signalling pathway [28]. To further examine whether LEF1 suppression by mangiferin deactivated Wnt signalling, we quantified the transcriptional products of the Wnt pathway in mangiferin-treated HCC cells. Significant down-regulation of LEF1 trans-activated genes, MYC, axin2, MMP2 and CCND1 was observed in MHCC97L and HLF cells after mangiferin treatment (Fig. 5A). In line with these findings, nuclear localization of $L E F 1$ in MHCC97L cells was blocked following mangiferin treatment

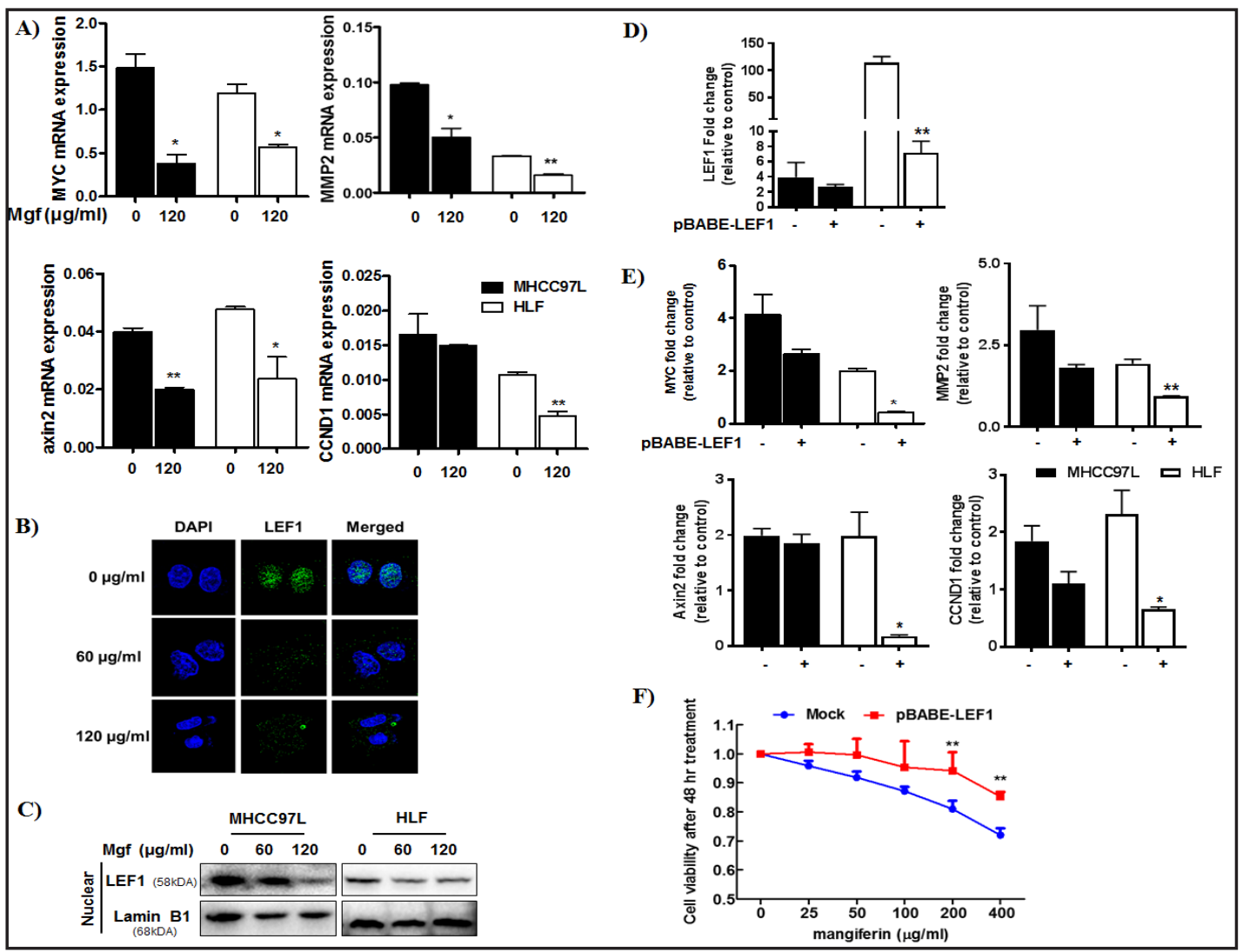

Fig. 5. Mangiferin reduced LEF1 nuclear translocation and trans-activated gene expression. A: The mRNA expression of MYC, MMP2, axin2 and CCND1 after mangiferin treatment. Mangiferin at $120 \mu \mathrm{g} / \mathrm{mL}$ consistently reduced LEF1 trans-activated genes in MHCC97L and HLF cells. B: Reduced nuclear accumulation of LEF1 was observed in MHCC97L cells treated with mangiferin. DAPI was used as a nuclear counterstain. C: Mangiferin reduced nuclear LEF1 protein expression in MHCC97L and HLF cells. D: MHCC97L and HLF cells were transduced with a retroviral vector expressing pBABE-LEF1 and relative LEF1 mRNA fold change was determined by RT-qPCR. Overexpression of LEF1 diminished LEF1 gene repression by mangiferin. E: Overexpression of LEF1 reduced the differences between the control- and mangiferin-treated cells in their expression levels of LEF1 trans-activated genes. F: The inhibitory effect of mangiferin on cellular expansion was abolished by LEF1 overexpression. MHCC97L cells were transduced with a retroviral vector expressing pBABE-LEF1 or a control vector. The LEF1-overexpressing cells and the cells transduced with the control vector were treated with serial concentrations of mangiferin and their viability was determined by MTT assay. ${ }^{*} \mathrm{p}<0.05 ;{ }^{* *} \mathrm{p}<0.01$. 
(Fig. 5B). Immuno-blot analysis also revealed that mangiferin treatment led to a dosedependent reduction in nuclear LEF1 in MHCC97L and HLF cells (Fig. 5C). To further assess the role of $L E F 1$ in mangiferin-mediated alterations in Wnt-related target gene expression, we transduced MHCC97L and HLF cells with a retroviral vector expressing pBABE-LEF1 [29]. The gain-of-function of LEF1 diminished Wnt gene repression by mangiferin (Fig. 5D). Furthermore, the differences between control- and mangiferin-treated cells regarding expression levels of Wnt-trans-activated genes were diminished by LEF1-overexpression (induced by transfection with pBABE-LEF1) but not by unaltered LEF1 expression (after transfection with an empty vector) (Fig. 5E). Consistent with the functional significance of increased Wnt-target genes, the inhibitory effect of mangiferin on cellular expansion was abolished by LEF1 overexpression (Fig. 5F). All these results further support the essential role of $L E F 1$ inhibition in mediating suppression of Wnt signalling by mangiferin.

\section{Mangiferin disrupted WT1-associated transactivation in HCC cells}

The activation of the canonical Wnt pathway involves stabilization of free $\beta$-catenin, followed by transcriptional activation of LEF1 through nuclear binding with $\beta$-catenin and initiation of Wnt-regulated downstream genes [11]. To further determine whether the inhibition of the Wnt pathway by mangiferin in HCC cells relies on $\beta$-catenin, we used recombinant protein Wnt3a to specifically activate $\beta$-catenin signalling. Addition of Wnt3a merely triggered the activation of LEF1. In addition, mangiferin treatment of HCC cells

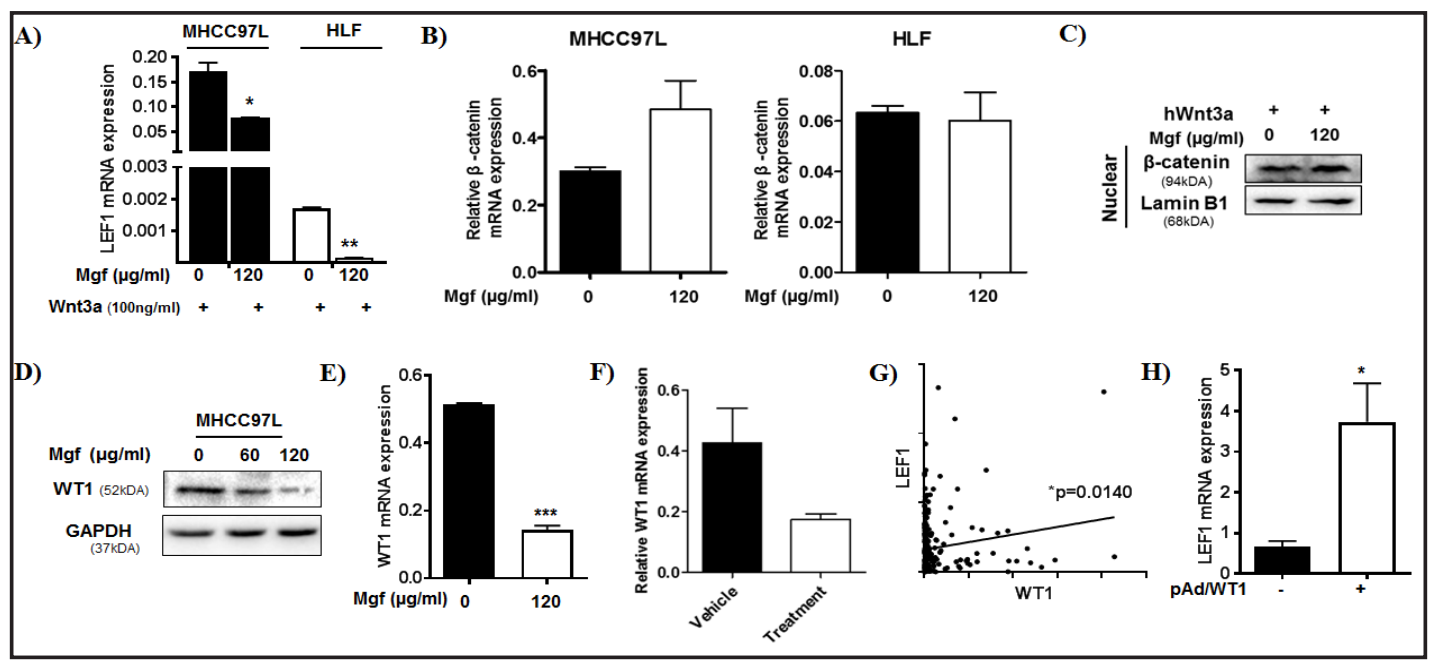

Fig. 6. WT1-associated LEF1 transactivation was disrupted by mangiferin treatment. A: Relative LEF1 mRNA expression in MHCC97L and HLF cells. Mangiferin significantly reduced LEF1 expression in the presence of the Wnt3a signal. B: mRNA expression of $\beta$-catenin. MHCC97L cells with vs. without LEF1 overexpression (induced with the pBABE-LEF1 vs. a control vector, respectively) were subjected to mangiferin treatment and mRNA expression was determined by RT-qPCR. C: The expression of nuclear $\beta$-catenin protein. MHCC97L cells with and without LEF1 overexpression were subjected to mangiferin treatment and proteins were analysed using an immunoblotting assay. Mangiferin treatment did not alter transcriptional and translational changes of $\beta$-catenin in HCC cells. D: The WT1 protein expression was determined by immunoblotting assay. Mangiferin reduced WT1 levels in MHCC $97 \mathrm{~L}$ cells in a dose-dependent manner. E: WT1 mRNA expression after mangiferin treatment was determined by RT-qPCR. Mangiferin at $120 \mu \mathrm{g} / \mathrm{mL}$ significantly reduced WT1 mRNA expression in MHCC97L cells. F: Decreased WT1 expression in hepatic tumour tissues after mangiferin treatment $(\mathrm{n}=5)$. WT1 mRNA expression was determined by RT-qPCR of hepatic orthotopic tumours extracted from mice treated with a control vehicle or mangiferin. G: The correlation between mRNA expression of WT1 and LEF1 in tumours from patients with HCC $(n=244)$. H: MHCC97L cells were transduced with the pAd/WT1-IRES-nAmCyan vector targeting WT1, and the relative LEF1 mRNA expression was determined by RT-qPCR. Overexpression of WT1 consistently upregulated LEF1 mRNA expression. ${ }^{*} \mathrm{p}<0.05 ;{ }^{* * *} \mathrm{p}<0.001$.

\section{KARGER}


containing Wnt3a led to LEF1 reduction similar to that observed in cells without Wnt3a (Fig. 6A). These results suggest that $\beta$-catenin is not involved in LEF1 expression and the subsequent deactivation of Wnt signalling. This was further supported by the observation that transcriptional and translational activation of $\beta$-catenin remained unaltered in mangiferin-treated HCC cells upon Wnt stimulation (Fig. 6B \& 6C).

The Wilms' tumour 1 gene (WT1) is overexpressed in hepatic cancer cells and promotes cancer cell dedifferentiation and drug resistance [30]. We found that WT1 was downregulated at both transcriptional and translational levels in mangiferin-treated cells (Fig. 6D \& 6E). Similar results were also observed in mangiferin-treated hepatic tissue (Fig. 6F). We therefore hypothesized that expression of LEF1 is associated with WT1 expression in HCC cells. By analysing 244 pairs of data from the TCGA database, we found that WT1 and LEF1 mRNA expression were positively correlated (Fig. 6G), indicating that LEF1 expression might be regulated by WT1. To further examine the role of WT1 in regulating LEF1 gene expression, MHCC97L cells were transfected with the pAd/WT1-IRES-nAmCyan vector, targeting WT1. Accordingly, in the absence of mangiferin, WT1 overexpression led to increased expression of $L E F 1$, indicating the transcriptional activation of $L E F 1$ by $W T 1$ (Fig. $6 \mathrm{H}$ ). Our findings suggest that mangiferin repressed transcriptional activation of LEF1 in a WT1-dependent but $\beta$-catenin-independent manner.

\section{WT1 activated transcription by associating with its promoter region}

A recent genome-wide screen revealed that WT1 has multiple targets in cells, including several proteins involved in the Wnt pathway [31], including LEF1. Another study of taste cells showed that knockdown of WT1 reduced the expression of LEF1 [32], which was in accordance with our observations in described in the preceding section. To determine the mechanism underlying transcriptional activation of LEF1 by WT1, we performed ChIP

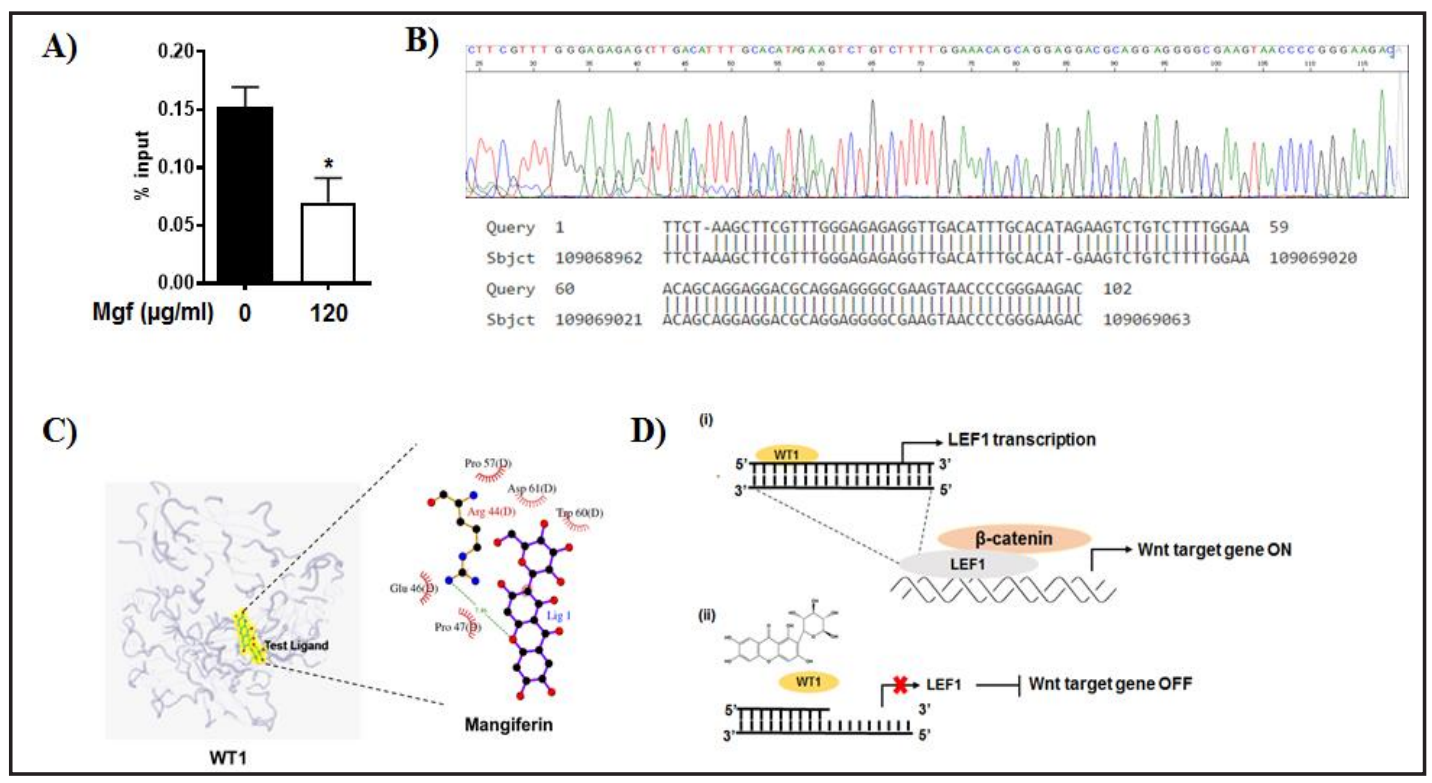

Fig. 7. Association of WT1 with the LEF1 promoter region activated LEF1 transcription A: DNA binding of WT1 to the LEF1 promoter was assayed by ChIP-qPCR. Binding of WT1 to the LEF1 promoter was reduced after mangiferin treatment. Enrichment was determined as \% of input in two independent experiments. B: The WT1 binding site on the LEF1 promoter region was confirmed by Sanger sequencing analysis. C: Mode of interaction between mangiferin and WT1. D: Schematic diagram proposing the working model of mangiferin function in silencing Wnt target gene expression. In HCC cells, the association of WT1 with the LEF1 promoter region induces LEF1 transcriptional activity and its subsequent Wnt target gene expression (step 1); mangiferin intervention suppresses LEF1 expression through reduced binding of WT1 to the LEF1 promoter region (step 2); these two steps lead to Wnt target gene suppression. 


\section{Cellular Physiology Cell Physiol Biochem 2018;47:1819-1834 \\ \begin{tabular}{l|l} 
DOI: 10.1159/000491063 & Ond 2018 The Author(s). Published by S. Karger AG, Basel \\
www.karger.com/cpb
\end{tabular}}

Tan et al.: Mangiferin Suppressed HCC via WT1-Mediated LEF1 Deactivation

assays with antibodies to WT1. We detected the promoter region of LEF1 in WT1 antibodyprecipitated nucleotides, which indicated that WT1 may activate LEF1 transcription through direct binding to its promoter region. More importantly, the occupancy of WT1 on the LEF1 promoter site was significantly reduced following mangiferin treatment (Fig.7A). Sanger sequencing analysis further confirmed that the WT1 binding site was located in the LEF1 promoter region (Fig. 7B). To further investigate possible interactions between mangiferin and WT1, we performed in silico molecular docking analysis of mangiferin with the different binding sites of WT1. The mangiferin structure could strongly bind to the DNA binding site of WT1, according to a docking score of 5.722 pKd (Fig. 7C). Overall, our findings together with others reports, unveiled WT1 as a transcription factor of $L E F 1$, enhancing its expression by binding to the promoter region. Also, mangiferin suppressed $L E F 1$ expression by decreasing binding of WT1 to the LEF1 promoter region.

\section{Discussion}

Several studies in the last 5 years have demonstrated an inhibitory effect of mangiferin on the growth and proliferation of myriad types of cancer cells, including cells from breast adenocarcinoma [33], prostate cancer [34], leukaemia [35], glioma [36], and nasopharyngeal cancer [37]. Yet, all these experiments were implemented at the cellular level and in vitro cellular models may not mimic the clinical cancer pathogenesis. Tumorigenesis is a complicated process involving interactions between tumour cells and immune cells, the extracellular matrix, and stem cell niches. These interactions may not all be modelled accurately in vitro. A recent study demonstrated a chemo preventive effect of mangiferin in a breast cancer xenograft model [23]. Mangiferin administered 1 week before subcutaneous xenotransplantation of cancer cells diminished tumour growth. This effect was considered a result of the deregulation of Wnt/ $\beta$-catenin signalling. In our study, to systematically investigate the role of mangiferin on HCC growth, we used an orthotopic HCC implantation model that represents well the critical tumorigenesis events involved in cancer cell invasion, whereby hepatocytes are replaced by neoplastic cells and tumour neovascularization occurs. We found that treatment with mangiferin, in comparison with the control vehicle, was associated with a less invasive and less proliferative pattern upon tissue examination. Additional molecular analyses further confirmed the inhibitory effect of mangiferin on HCC cell proliferation and partially elucidated a mechanism of action. Specifically, the Wnt pathway was inhibited by mangiferin independent of changes to the intracellular level of $\beta$-catenin. Instead, LEF1, the direct executor of Wnt signalling, was prominently suppressed. This suggested that mangiferin may target multiple effector molecules in the Wnt pathway in inhibiting the growth of different types of cancers. Given that clinical and investigational treatments that target individual molecules are often compromised by the frequent mutation of cancer cells [38], the multi-target property of mangiferin may indicate its potential as a promising Wnt inhibitor for cancer treatment.

Classical activation of the Wnt pathway is initiated by the stabilization of $\beta$-catenin as well as its translocation from the cellular membrane to intracellular regions upon ligand association with Wnt receptors [39]. Translocation of $\beta$-catenin promotes LEF1 activation by forcing it to disengage from Groucho proteins, so that transcription activity of LEF1 is executed [11]. However, several studies have proposed that LEF1 plays a $\beta$-cateninindependent role in the Wnt signalling $[17,18,40]$. Grumolato et al. reported the LEF1dependent activation of Wht signalling was observed without the association of $\beta$-catenin with LEF1 [17, 40]. TCF1 and LEF1 mutants that lack $\beta$-catenin binding sites also physically interact with transcriptional factor ATF2 for Wnt signalling activation [40]. Other studies revealed that factors like ALY and Smad may cooperatively act on LEF1 to activate Wnt signalling in a $\beta$-catenin-independent manner $[17,18]$. In our study, we observed the direct transcriptional repression of $L E F 1$ by mangiferin regardless of the initiation of upstream Wnt/ $\beta$-catenin through ligand binding. A previous study stated that Wnt ligand activation 


\section{Cellular Physiology Cell Physiol Biochem 2018;47:1819-1834 \begin{tabular}{l|l} 
DOI: 10.1159/000491063 & $\begin{array}{l}\text { O } 2018 \text { The Author(s). Published by S. Karger AG, Basel } \\
\text { www.karger.com/cpb }\end{array}$
\end{tabular} \\ Tan et al.: Mangiferin Suppressed HCC via WT1-Mediated LEF1 Deactivation}

caused elevated LEF1 expression in a $\beta$-catenin-independent and LEF1-dependent manner [40], which supports our finding of $\beta$-catenin-independent $L E F 1$ repression by mangiferin in HCC cells. $L E F 1$ related signalling is a multi-targeted regulatory mechanism in which the aberrant activation of $L E F 1$ results in cancer development by promoting processes such as invasion, proliferation, and self-renewal of cancer cells [28, 41, 42]. Our molecular finding that mangiferin represses $L E F 1$ target genes accords with these previous studies, especially given our cellular finding mangiferin restricted HCC cell proliferation, migration, and chemotactic properties.

Furthermore, we found that mangiferin-mediated LEF1 suppression was associated with WT1 in HCC cells. A previous study showed that WT1 is overexpressed in hepatic cancer cells and promote cancer cell growth and drug resistance [30]. Also, WT1 mutation has been widely detected in different types of cancer cells [43]. However, the role of WT1 as a tumour suppressor or promoter remains enigmatic [44]. In our study, gain-of-function targeting of WT1 up-regulated LEF1 expression in MHCC97L cells, suggesting that WT1 is a transcriptional activator of $L E F 1$. This observation accords with the finding of Gao et al. that knockdown of WT1 reduced LEF1 expression [32]. Notably, we demonstrated that WT1, as a transcriptional activator, could directly bind to the promoter region of $L E F 1$. Treatment with mangiferin reduced this association and therefore suppressed LEF1 expression and subsequent Wnt signal activation (Fig. 7D). A previous genome-wide screening revealed that the Wnt pathway is the putative target of WT1 [31], and our findings provide further insight into the mechanism by which WT1 connects to and regulates Wnt activity and its related signalling protein.

In conclusion, the current study showed the in vivo suppressive effect of mangiferin on HCC using an orthotopic implantation model. Cellular investigations demonstrated the multifaceted interruption of HCC cell growth by mangiferin through various mechanisms, including inhibition of HCC cell expansion and invasion. Furthermore, our mechanistic study indicated that the HCC inhibitory effect of mangiferin was mediated through transcriptional repression of LEF1. LEF1 suppression by mangiferin was evidenced by the observations of: (i) reduced LEF1 expression in both hepatic tumour tissues and HCC cells treated with mangiferin; (ii) downregulation of LEF1 trans-activated genes in MHCC97L and HLF cells, following mangiferin treatment; and (iii) overexpression of $L E F 1$ diminished the downregulation of LEF1 trans-activated genes by mangiferin. Finally, the mangiferinmediated down-regulation of LEF1 was independent of $\beta$-catenin but involved the disruption of the interaction between WT1 and the LEF1 promoter. Our study demonstrates LEF1 transcriptional up-regulation through association with WT1 protein, and subsequent Wnt activation and HCC growth. The study also indicates that mangiferin is a potential Wnt inhibitor that targets WT1/LEF1-mediated Wnt activation for HCC treatment.

\section{Acknowledgements}

The authors would like to express our gratitude to Mr. Keith Wong, Ms. Cindy Lee, Mr. Alex Shek and Faculty Core Facility for their technical support. This work was partially supported by the research council of the University of Hong Kong [project code: 104003422, 104004092 and 104004460]; Wong's donation [project code: 200006276]; the donation of Gaia Family Trust, New Zealand [project code: 200007008]; Research Grant from Guizhou Bailing Pharmaceutical Company (Project Code: 26607830); the Research Grants Committee (RGC) of Hong Kong, HKSAR [project code: 766211 and 17152116] and Shenzhen Basic Research Program (Project code: JCYJ20140903112959964).

\section{Disclosure Statement}

The authors have no competing financial interests to declare.

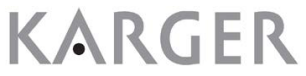




\section{Cellular Physiology Cell Physiol Biochem 2018;47:1819-1834 \begin{tabular}{l|l} 
and Biochemistry Published ontine: June 28, 2018 & $\begin{array}{l}\text { (c) } 2018 \text { The Author(s). Published by S. Karger AG, Basel } \\
\text { www.karger.com/cpb }\end{array}$
\end{tabular}}

Tan et al.: Mangiferin Suppressed HCC via WT1-Mediated LEF1 Deactivation

\section{References}

1 Fitzmaurice C, Allen C, Barber RM, Barregard L, Bhutta ZA, Brenner H, Dicker DJ, Chimed-Orchir O, Dandona R, Dandona L, Fleming T, Forouzanfar MH, Hancock J, Hay RJ, Hunter-Merrill R, Huynh C, Hosgood HD, Johnson CO, Jonas JB, Khubchandani J et al.: Global, Regional, and National Cancer Incidence, Mortality, Years of Life Lost, Years Lived With Disability, and Disability-Adjusted Life-years for 32 Cancer Groups, 1990 to 2015: A Systematic Analysis for the Global Burden of Disease Study. JAMA Oncol 2017;3:524-548.

-2 Altekruse SF, McGlynn KA, Reichman ME: Hepatocellular carcinoma incidence, mortality, and survival trends in the United States from 1975 to 2005. J Clin Oncol 2009;27:1485-1491.

3 Schwartz M, Roayaie S, Konstadoulakis M: Strategies for the management of hepatocellular carcinoma. Nat Clin Pract Oncol 2007;4:424-432.

4 Trevisani F, Cantarini MC, Wands JR, Bernardi M: Recent advances in the natural history of hepatocellular carcinoma. Carcinogenesis 2008;29:1299-1305.

5 Kim M, Lee HC, Tsedensodnom 0, Hartley R, Lim YS, Yu E, Merle P, Wands JR: Functional interaction between Wnt3 and Frizzled-7 leads to activation of the Wnt/beta-catenin signaling pathway in hepatocellular carcinoma cells. J Hepatol 2008;48:780-791.

6 Pez F, Lopez A, Kim M, Wands JR, Caron de Fromentel C, Merle P: Wnt signaling and hepatocarcinogenesis: molecular targets for the development of innovative anticancer drugs. J Hepatol 2013;59:1107-1117.

7 Waisberg J, Saba GT: Wnt-/- $\beta$-catenin pathway signaling in human hepatocellular carcinoma. World J Hepatol 2015;7:2631-2635.

-8 Yamashita T, Ji J, Budhu A, Forgues M, Yang W, Wang HY, Jia H, Ye Q Qin LX, Wauthier E, Reid LM, Minato H, Honda M, Kaneko S, Tang ZY, Wang XW: EpCAM-Positive Hepatocellular Carcinoma Cells Are TumorInitiating Cells With Stem/Progenitor Cell Features. Gastroenterology 2009;136:1012-1024.e1014.

-9 Mani SKK, Zhang H, Diab A, Pascuzzi PE, Lefrançois L, Fares N, Bancel B, Merle P, Andrisani O: EpCAMregulated intramembrane proteolysis induces a cancer stem cell-like gene signature in hepatitis B virusinfected hepatocytes. Journal of Hepatology 2016;65:888-898.

10 MacDonald BT, He X: Frizzled and LRP5/6 Receptors for Wnt/ $\beta$-Catenin Signaling. Cold Spring Harb Perspect Biol 2012;4:

11 Cadigan KM, Waterman ML: TCF/LEFs and Wnt signaling in the nucleus. Cold Spring Harb Perspect Biol 2012;4:

-12 Huang H, Fujii H, Sankila A, Mahler-Araujo BM, Matsuda M, Cathomas G, Ohgaki H: \&\#x3b2;-Catenin Mutations Are Frequent in Human Hepatocellular Carcinomas Associated with Hepatitis C Virus Infection. The American Journal of Pathology 155:1795-1801.

-13 Yin Y, Li F, Li S, Cai J, Shi J, Jiang Y: TLR4 Influences Hepatitis B Virus Related Hepatocellular Carcinoma by Regulating the Wnt/ $\beta$-Catenin Pathway. Cellular Physiology and Biochemistry 2017;42:469-479.

14 Wong CM, Fan ST, Ng IO: beta-Catenin mutation and overexpression in hepatocellular carcinoma: clinicopathologic and prognostic significance. Cancer 2001;92:136-145.

15 Damsky WE, Curley DP, Santhanakrishnan M, Rosenbaum LE, Platt JT, Gould Rothberg BE, Taketo MM, Dankort D, Rimm DL, McMahon M, Bosenberg M: beta-catenin signaling controls metastasis in Brafactivated Pten-deficient melanomas. Cancer Cell 2011;20:741-754.

16 Shang S, Hua F, Hu ZW: The regulation of beta-catenin activity and function in cancer: therapeutic opportunities. Oncotarget 2017;8:33972-33989.

17 Labbe E, Letamendia A, Attisano L: Association of Smads with lymphoid enhancer binding factor $1 / \mathrm{T}$ cellspecific factor mediates cooperative signaling by the transforming growth factor-beta and wnt pathways. Proc Natl Acad Sci U S A 2000;97:8358-8363.

18 Hsu SC, Galceran J, Grosschedl R: Modulation of transcriptional regulation by LEF-1 in response to Wnt-1 signaling and association with beta-catenin. Mol Cell Biol 1998;18:4807-4818.

19 Tsedensodnom O, Koga H, Rosenberg SA, Nambotin SB, Carroll JJ, Wands JR, Kim M: Identification of T-cell factor-4 isoforms that contribute to the malignant phenotype of hepatocellular carcinoma cells. Exp Cell Res 2011;317:920-931.

-20 Masibo M, He Q: Major Mango Polyphenols and Their Potential Significance to Human Health. Comprehensive Reviews in Food Science and Food Safety 2008;7:309-319.

21 Nunez Selles AJ, Daglia M, Rastrelli L: The potential role of mangiferin in cancer treatment through its immunomodulatory, anti-angiogenic, apoptopic, and gene regulatory effects. Biofactors 2016;42:475-491.

22 Gold-Smith F, Fernandez A, Bishop K: Mangiferin and Cancer: Mechanisms of Action. Nutrients 2016;8: 


\section{Cellular Physiology Cell Physiol Biochem 2018;47:1819-1834

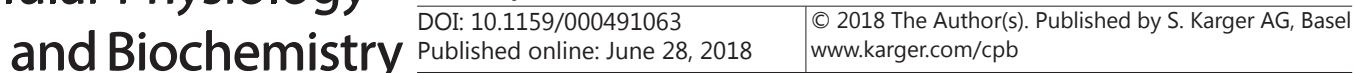

Tan et al.: Mangiferin Suppressed HCC via WT1-Mediated LEF1 Deactivation

23 Li H, Huang J, Yang B, Xiang T, Yin X, Peng W, Cheng W, Wan J, Luo F, Li H, Ren G: Mangiferin exerts antitumor activity in breast cancer cells by regulating matrix metalloproteinases, epithelial to mesenchymal transition, and beta-catenin signaling pathway. Toxicol Appl Pharmacol 2013;272:180-190.

24 Tan HY, Wang N, Tsao SW, Che CM, Yuen MF, Feng Y: IRE1alpha inhibition by natural compound genipin on tumour associated macrophages reduces growth of hepatocellular carcinoma. Oncotarget 2016;7:4379243804.

25 Hodo Y, Honda M, Tanaka A, Nomura Y, Arai K, Yamashita T, Sakai Y, Yamashita T, Mizukoshi E, Sakai A, Sasaki M, Nakanuma Y, Moriyama M, Kaneko S: Association of interleukin-28B genotype and hepatocellular carcinoma recurrence in patients with chronic hepatitis C. Clin Cancer Res 2013;19:1827-1837.

-26 Cerami E, Gao J, Dogrusoz U, Gross BE, Sumer SO, Aksoy BA, Jacobsen A, Byrne CJ, Heuer ML, Larsson E, Antipin Y, Reva B, Goldberg AP, Sander C, Schultz N: The cBio cancer genomics portal: an open platform for exploring multidimensional cancer genomics data. Cancer Discov 2012;2:401-404.

-27 Gao J, Aksoy BA, Dogrusoz U, Dresdner G, Gross B, Sumer SO, Sun Y, Jacobsen A, Sinha R, Larsson E, Cerami E, Sander C, Schultz N: Integrative analysis of complex cancer genomics and clinical profiles using the cBioPortal. Sci Signal 2013;6:pl1.

28 Huang FI, Chen YL, Chang CN, Yuan RH, Jeng YM: Hepatocyte growth factor activates Wnt pathway by transcriptional activation of LEF1 to facilitate tumor invasion. Carcinogenesis 2012;33:1142-1148.

29 Nguyen DX, Chiang AC, Zhang XH, Kim JY, Kris MG, Ladanyi M, Gerald WL, Massague J: WNT/TCF signaling through LEF1 and HOXB9 mediates lung adenocarcinoma metastasis. Cell 2009;138:51-62.

-30 Perugorria MJ, Castillo J, Latasa MU, Goni S, Segura V, Sangro B, Prieto J, Avila MA, Berasain C: Wilms' tumor 1 gene expression in hepatocellular carcinoma promotes cell dedifferentiation and resistance to chemotherapy. Cancer Res 2009;69:1358-1367.

-31 Kim MK, McGarry TJ, P OB, Flatow JM, Golden AA, Licht JD: An integrated genome screen identifies the Wnt signaling pathway as a major target of WT1. Proc Natl Acad Sci U S A 2009;106:11154-11159.

-32 Gao Y, Toska E, Denmon D, Roberts SG, Medler KF: WT1 regulates the development of the posterior taste field. Development 2014;141:2271-2278.

33 Cuccioloni M, Bonfili L, Mozzicafreddo M: Mangiferin blocks proliferation and induces apoptosis of breast cancer cells via suppression of the mevalonate pathway and by proteasome inhibition. 2016;7:4299-4309.

-34 Li M, Ma H, Yang L, Li P: Mangiferin inhibition of proliferation and induction of apoptosis in human prostate cancer cells is correlated with downregulation of B-cell lymphoma-2 and upregulation of microRNA-182. Oncol Lett 2016;11:817-822.

-35 Peng ZG, Yao YB, Yang J, Tang YL, Huang X: Mangiferin induces cell cycle arrest at G2/M phase through ATRChk1 pathway in HL-60 leukemia cells. Genet Mol Res 2015;14:4989-5002.

-36 Xiao J, Liu L, Zhong Z, Xiao C, Zhang J: Mangiferin regulates proliferation and apoptosis in glioma cells by induction of microRNA-15b and inhibition of MMP-9 expression. Oncol Rep 2015;33:2815-2820.

-37 Pan LL, Wang AY, Huang YQ Luo Y, Ling M: Mangiferin induces apoptosis by regulating Bcl-2 and Bax expression in the CNE2 nasopharyngeal carcinoma cell line. Asian Pac J Cancer Prev 2014;15:7065-7068.

38 Torti D, Trusolino L: Oncogene addiction as a foundational rationale for targeted anti-cancer therapy: promises and perils. EMBO Mol Med 2011;3:623-636.

-39 MacDonald BT, Tamai K, He X: Wnt/beta-catenin signaling: components, mechanisms, and diseases. Dev Cell 2009;17:9-26.

40 Grumolato L, Liu G, Haremaki T, Mungamuri SK, Mong P, Akiri G, Lopez-Bergami P, Arita A, Anouar Y, Mlodzik M, Ronai ZA, Brody J, Weinstein DC, Aaronson SA: beta-Catenin-independent activation of TCF1/ LEF1 in human hematopoietic tumor cells through interaction with ATF2 transcription factors. PLoS Genet 2013;9:e1003603.

41 Gao X, Mi Y, Ma Y, Jin W: LEF1 regulates glioblastoma cell proliferation, migration, invasion, and cancer stem-like cell self-renewal. Tumour Biol 2014;35:11505-11511.

42 Zhang Z, Kim K, Li X, Moreno M, Sharp T, Goodheart MJ, Safe S, Dupuy AJ, Amendt BA: MicroRNA-26b represses colon cancer cell proliferation by inhibiting lymphoid enhancer factor 1 expression. Mol Cancer Ther 2014;13:1942-1951.

43 Wang Y, Xiao M, Chen X, Chen L, Xu Y, Lv L, Wang P, Yang H, Ma S, Lin H, Jiao B, Ren R, Ye D, Guan KL, Xiong Y: WT1 recruits TET2 to regulate its target gene expression and suppress leukemia cell proliferation. Mol Cell 2015;57:662-673.

44 Huff V: Wilms' tumours: about tumour suppressor genes, an oncogene and a chameleon gene. Nat Rev Cancer 2011;11:111-121. 